\title{
Réplica a Davidson sobre a Ética do Descasamento da Maturidade de Empréstimos e o Sistema Bancário de Reservas Fracionárias*
}

\author{
Walter Block ${ }^{* *}$ \\ William Barnett II**
}

\begin{abstract}
Resumo: Davidson (2014) defende a posição de que não há nada de antiético a respeito do descasamento da maturidade de empréstimos, em particular quando um banco obtém dinheiro emprestado por um horizonte de tempo mais curto do que quando o empresta. O presente artigo contesta a sua posição e sustenta que, além de tal prática ser antiética, deveria também ser considerada ilegal.
\end{abstract}

Palavras-Chave: Reservas fracionárias, Sistema bancário, Descasamento da maturidade de empréstimos.

\section{Rejoinder to Davidson on the Ethics of Loan Maturity Misma- tching and Fractional Reserve Banking}

\begin{abstract}
Davidson (2014) takes the position that there is nothing unethical about loan maturity mismatching, particularly when a bank borrows money for a shorter time horizon than when it lends it out. The present paper takes issue with her position, and maintains that not only is this practice unethical, it should be outlawed.
\end{abstract}

Key words: Fractional reserves, Banking, Loan maturity mismatching.

Classificação JEL: E42.

\footnotetext{
*Traduzido do original em inglês para o português por Claudio A. Téllez-Zepeda.

"Walter E. Block é Harold E.Wirth Eminent Scholar Endowed Chair e Professor de Economia da Escola de Negócios da Loyola University, em New Orleans.

E-mail: wblock@loyno.edu

*** William Barnett II é Professor de Economia e Chase Bank Distinguished Professor de Negócios Internacionais da Escola de Negócios da Loyola University, em New Orleans.

E-mail: wbarnett@loyno.edu
} 


\section{I - INTRODUÇÃo}

Tanto Davidson ${ }^{1}$ quanto os autores deste artigo estão completamente de acordo com relação à adequação ética do sistema bancário de reservas fracionárias (FRB): nós três rejeitamos todas as reivindicações em favor dessa prática. Todos concordamos em que o FRB não deveria existir em uma sociedade livre e defendemos, com embasamento ético, sua proibição na atual economia mista.

Entretanto, afastamo-nos quando se trata de tomar empréstimos no curto prazo e emprestar no longo prazo (BSLL) ${ }^{2}$. Quais são os problemas com isso, de acordo com nossa concepção? Em nossa percepção, o BSLL e o FRB ocupam o mesmo espaço ético, dado que o FRB não é mais do que um exemplo daquilo que o BSLL configura o caso geral. Colocado em termos de um diagrama de Venn, teríamos o BSLL como um círculo e o FRB como um

\footnotetext{
${ }^{1}$ Todas as referências da Davidson, salvo menção em contrário, referir-se-ão ao seguinte artigo: DAVIDSON, Laura. Ethical Differences Between Loan Maturity Mismatching and Fractional Reserve Banking: A Natural Law Approach. Journal of Business Ethics, Vol. 131, No. 1 (September 2015): 9-18. Entretanto ver, também o artigo: DAVIDSON, Laura. The Economic Consequences of Loan Maturity Mismatching in the Unhampered Economy. The Quarterly Journal of Austrian Economics, Vol. 17, No. 1 (Spring 2014): 6791. Seu ensaio no Journal of Business Ethics critica o seguinte artigo: BARNETT II, William \& BLOCK, Walter E. Rejoinder to Bagus and Howden on Borrowing Short and Lending Long. Journal of Business Ethics, Vol. 100, No. 2 (May 2011): 229-238, ao qual refere-se equivocadamente como sendo de 2010. Se não há dano, não há problema.
}

${ }^{2} \mathrm{O}$ descasamento da maturidade de empréstimos (LMM, loan maturity mismatching) consiste em tomar empréstimo no curto prazo e emprestar no longo prazo (BSLL, borrowing short and lending long) e em tomar empréstimo no longo prazo e emprestar no curto prazo (BLLS, borrowing long and lending short). Em outras palavras, $L M M=$ BSLL + BLLS. Davidson discute o primeiro caso destas duas práticas bancárias distintas. Nesta resposta, concentramo-nos mais estritamente no BSLL. N. do T.: Optei por preservar as abreviações em inglês: $\mathrm{LMM}=$ "loan maturity mismatching", BLLS = "borrowing long and lending short" e assim por diante. círculo menor, totalmente contido dentro do primeiro círculo. Considere que, em ambos os casos, A, o poupador, deposita dinheiro com $B$, o banqueiro, que por sua vez empresta esse dinheiro para $C$, o tomador de empréstimo ou investidor. A diferença é que, no caso do BSLL, A aloca fundos com B, não à sua ordem (de A), mas por um período de tempo especificado, e B empresta esses fundos a C por um período que excede (e, frequentemente, excede em muito) o período pelo qual A colocou os fundos à disposição de B. Em contraste, no caso do FRB, A deposita dinheiro à vista, o que significa que A pode obter seu dinheiro de volta instantaneamente, à sua ordem $^{3}$, enquanto B empresta esses fundos para C, em geral por um período de tempo determinado (obviamente, não instantâneo) ${ }^{4}$. Ou seja, C também pode demandar o dinheiro de acordo com sua própria conveniência. Sob o BSLL, suponha que A aloque fundos com B por um tempo de depósito de um ano, e então B empresta esse dinheiro para $\mathrm{C}$ por 10 anos. Para o primeiro ano, concedemos que o BSLL e o FRB são de fato muito distintos. Nenhum problema emerge com relação ao BSLL. B não deve nenhum dinheiro a ninguém durante esse período. Entretanto, quando termina o primeiro ano, surgem os problemas éticos. B deve a A o dinheiro que lhe corresponde, o qual B emprestou para C por um período maior do que um ano. Caso B tivesse emprestado os fundos para $C$ durante não mais do que um ano, nenhum problema ético teria surgido. Entretanto, este não é o caso em nosso exemplo concreto. C deverá pagar a B, obviamente, porém dispõe de mais nove anos para fazer isso.

Na verdade, a dificuldade moral começou antes mesmo que isso. O problema ético surgiu no momento em que $B$ emprestou os fundos que A depositou em B, com data de

\footnotetext{
${ }^{3}$ Tão rápido quanto a ação humana pode permitir.

4 Bancos realizam alguns empréstimos que podem ser cobrados à ordem; entretanto, a maior parte dos empréstimos bancários são realizados por períodos de tempo especificados.
} 
pagamento que ultrapassou o fim do período de depósito de um ano; ou seja, no momento em que $B$ realizou dois contratos incompatíveis 5 . Neste exemplo, B tomou emprestado de A no curto prazo e emprestou o dinheiro de A para C por toda uma década. Isto não é somente antiético. Deveria ser, também, proibido por lei - e certamente o seria em uma sociedade libertária ${ }^{6}$. No caso do FRB, as dificuldades éticas e legais surgem logo no início. B realizou dois contratos incompatíveis e não dispõe dos recursos 7 para reembolsar A. Obviamente caso B seja solvente, ou seja, caso seus ativos excedam seus passivos, então poderá reembolsar A mediante a liquidação de alguns de seus ativos. Diante do tempo necessário para transformar ativos não monetários em fundos disponíveis imediatamente, que é o que A deseja e tem direito ao término desse ano, a única maneira para que isto possa ser feito de maneira verdadeiramente satisfatória, desde uma perspectiva ética, seria que B mantivesse parte suficiente de seu patrimônio em caixa para satisfazer às demandas de $\mathrm{A}^{8}$. O

\footnotetext{
${ }^{5}$ Assim, se tão logo que recebeu os fundos de A, B tivesse emprestado o dinheiro a $\mathrm{C}$ por qualquer período que excedesse um ano, B teria realizado contratos incompatíveis. Entretanto, se B não emprestasse os fundos até seis meses após tê-los recebido, então qualquer empréstimo para $\mathrm{C}$ por um período maior do que seis meses teria, da mesma maneira, dado origem a uma incompatibilidade contratual. Em todos esses casos, isto seria eticamente problemático.

6 Fundamentamos nossa argumentação na filosofia libertária, a qual distingue entre o que é imoral e o que deveria ser proibido por lei. $\mathrm{O}$ último caso é reservado às violações de direitos. Em contraste, "crimes" sem vítimas realizados entre adultos sob consentimento, como, por exemplo, o uso de drogas que causam dependência e a prostituição, podem ser considerados comportamentos antiéticos, porém seriam legais em uma sociedade livre. Para uma explicação mais detalhada do libertarianismo, ver: ROTHBARD, Murray N. The Ethics of Liberty. New York: New York University Press, 1982 [1998].
}

${ }^{7} \mathrm{~B}$ possui à sua disposição uma mera fração da quantia que deve a $\mathrm{A}$.

8 Seria possível argumentar que, caso B tivesse à disposição ativos não monetizados suficientes para argumento que Davidson e os autores deste trabalho compartilham com relação ao FRB é que há dois proprietários de 100 por cento do mesmo fundo, o que configura uma violação evidente dos direitos de propriedade privada, um dos pilares do libertarianismo9. Por exemplo, A deposita 100 dólares com B e recebe uma conta corrente com direitos de efetuar retiradas até este montante. Em seguida, B empresta 90 dólares a $C$, mantendo uma fração do depósito original, neste caso 10 dólares, ou 10 por cento, destinados a fazer pagamentos. Agora, $\mathrm{C}$ também possui um depósito à vista por estes 90 dólares emprestados a ele. Isto significa que tanto A quanto $\mathrm{C}$ detêm direitos de propriedade sobre estes 90 dólares sobrepostos. Por enquanto, estamos de acordo com Davidson. Também condenamos tais procedimentos como eticamente problemáticos; para sermos mais exatos, como totalmente errados.

Entretanto, divergimos nitidamente de Davidson em nossa avaliação muito distinta do BSLL. No momento em que B empresta a C depósitos de A por um período de tempo que ultrapassa o ano pelo qual A realizou o depósito, surge uma situação similar com respeito ao BSLL. A partir desse momento, $\mathrm{C}$ possui um claro direito sobre o dinheiro emprestado a ele por $\mathrm{B}^{10}$, porém o mesmo vale para $A$. Ademais, conforme sustentamos e demonstraremos a seguir, tanto o BSLL quanto o FRB são variações do velho esquema Ponzi.

oferecer a A, satisfazendo sua obrigação de reembolsar o depósito à vista, e se A aceitasse esta oferta, então não haveria problema. Ademais, isto seria correto de um ponto de vista prático. Por exemplo, B poderia oferecer a A títulos do Tesouro Americano negociados atualmente pelo dobro do total do depósito original e A poderia aceitar. Entretanto, a única maneira para que isto não fosse eticamente errado seria caso B pretendesse estar sempre nessa posição. Obviamente, se esse fosse o caso, em pouco tempo B estaria fora do mercado.

${ }^{9} \mathrm{O}$ outro é o princípio da não agressão (PNA): é uma ofensa passível de punição ameaçar ou dar início a atos violentos contra uma outra pessoa ou contra o que é de sua propriedade legítima.

${ }^{10}$ Durante mais nove anos. 
Após esta introdução, agora estamos prontos para responder, com detalhes, à excelente refutação que Davidson realiza a respeito da afirmação de que o FRB é moralmente ilícito e deveria ser proibido por lei, e aquilo que devemos considerar como sua análise não tão satisfatória sobre por que sua esplêndida percepção não deveria aplicar-se, também, ao caso do BSLL. Na seção II, lidaremos com a questão dos "bens futuros". A seção III conterá nossa tentativa de analisar o risco neste contexto. A tarefa da seção IV será incorporar a teoria da transferência de títulos (TTT) à nossa análise. Na seção $\mathrm{V}$, aplicaremos a TTT aos empréstimos a prazo. A seção VI será dedicada às nossas conclusões.

\section{II - Bens Futuros}

Começamos com o que deve ser considerado apenas um mero jogo de palavras. Davidson, em mais do que apenas umas poucas ocasiões, discute os "bens futuros". Porém, para Ludwig von Mises (1881-1973) e Murray Rothbard (1926-1995), não obstante o contrário, tais coisas não existem, ao menos não agora, fora do domínio da ficção científica. Sim, há títulos, agora, referentes a bens que esperamos que estejam disponíveis no futuro, porém que ainda não existem. A respeito disto, Davidson afirma que "bens futuros ainda precisam vir a existir"11. Isto é melhor do que meramente referir-se a eles, mas ainda não é algo que merece uma medalha. Não se trata de que "bens futuros ainda precisam vir a existir". Mais propriamente, trata-se de que, fora da ficção científica, eles não existem (agora) em absoluto. Não é que os bens futuros gozem, agora, de alguma espécie de existência bandida, talvez presentes de maneira invisível, porém aparecendo concretamente no futuro. Na verdade, agora não existem de nenhuma maneira, forma ou aspecto. Ademais, o que é

11 DAVIDSON. Ethical Differences Between Loan Maturity Mismatching and Fractional Reserve Banking: A Natural Law Approach. p. 5. ainda mais importante, podem nunca vir a existir. Davidson menciona "[...] uma troca entre um bem no presente e a promessa de entregar um bem futuro [...]"12. Simplesmente não há como "entregar um bem futuro". Por que não dizer, em vez disso, "entregar um bem no futuro"? A verdadeira troca é entre um bem presente por um outro bem presente; a saber, uma promessa.

\section{III - RISCO}

Discutiremos, agora, uma questão substantiva. Davidson começa citando Bagus e Howden ${ }^{13}$ no sentido em que, embora o BSLL seja "arriscado", não seria antiético ${ }^{14}$. Devemos observar que nem toda ação arriscada é ilegal ou imoral; nem toda ação ilegal é arriscada ou imoral; tampouco toda ação imoral é arriscada ou ilegal. Trata-se de três categorias diferentes que podem ser aplicadas às ações humanas. Nossa preocupação, aqui, é com a última categoria: imoralidade. Comparem o FRB com o BSLL. Na atualidade, em todas as economias avançadas, ambas essas práticas são legais e, obviamente, inerentemente arriscadas. Entretanto, enquanto tanto Davidson quanto os presentes autores estão de acordo quanto ao caráter antiético do primeiro, discordamos acerca do segundo. Ao contrário de nós, ela considera o segundo como moralmente aceitável. Por não perceber nada de

${ }^{12}$ Idem. Ibidem, p. 9.

${ }^{13}$ BAGUS, Phillipp \& HOWDEN, Davis. The Legitimacy of Loan Maturity Mismatching: A Risky, but not Fraudulent, Undertaking. Journal of Business Ethics, Vol. 90, No. 3 (2009): 399-406; BAGUS, Phillipp \& HOWDEN, Davis. Some Ethical Dilemmas of Modern Banking. Business Ethics: A European Review, Vol. 22, No. 3 (2013): 235-245.

${ }^{14} \mathrm{Na}$ verdade, toda ação humana envolve incerteza. O risco implica em ações que podem ser, pelo menos conceitualmente, repetidas ad infinitum e, portanto, às quais pode-se aplicar o cálculo de probabilidades. Esta proposição não é universalmente aceita, então em vez de debater esta questão aqui, assumiremos que o risco refere-se a qualquer evento futuro e incerto. 
antiético a respeito do BSLL, ela argumenta que deveria ser legal, enquanto nós acreditamos que é imoral e que deveria, também, ser ilegal ${ }^{15}$. Assim, nossa discordância refere-se à moralidade e legalidade do BSLL. Uma chave para nossa discordância é, também, o tema dos contratos incompatíveis.

De acordo com nossa concepção, a única maneira capaz de tornar o risco (na verdade, sua falta) relevante ocorre caso necessariamente participe da questão dos contratos incompatíveis, de maneira a transformá-los em contratos compatíveis. Entretanto, tal coisa só poderia acontecer, no caso do BSLL, se todo o risco associado a esses contratos fosse eliminado, o que é uma impossibilidade no mundo real. Na medida em que contratos de BSLL são arriscados, envolvem contratos que são incompatíveis ex ante.

\section{IV - TEORIA dA TransferêNCIA DE TÍtulos (TTT)}

Neste assunto, em seu artigo, Davidson baseia-se em Kinsella ${ }^{16}$ devido à sua "brilhante exposição da TTT". Dado que isto ocupa o cerne de sua defesa do BSLL, registraremos nossas objeções ao tratamento que este autor realiza da TTT. Na perspectiva de Davidson,

Considere o contrato: 'o prestamista concorda em transferir o título do dinheiro presente $X$ hoje, se o tomador do empréstimo concordar em transferir o título do dinheiro futuro $\mathrm{Y}$ no tempo de um ano'. Dado que o futuro é incerto, o contrato necessariamente inclui o termo implícito adicional 'se o tomador do empréstimo tiver o título de $Y$ para transferir'17.

\footnotetext{
${ }^{15}$ Obviamente, nem tudo o que é imoral deveria ser ilegal.

16 KINSELLA, Stephan N. A Libertarian Theory of Contract: Title Transfer, Binding Promises, and Inalienability. Journal of Libertarian Studies, Vol. 17, No. 2 (Spring 2003): 11-37.

17 DAVIDSON. Ethical Differences Between Loan Maturity Mismatching and Fractional Reserve Banking: A Natural Law Approach. p. 8
}

Não podemos permanecer ao lado de nossa ilustre colega na medida em que essa afirmação implícita está em causa. Não vemos o tal termo implícito. Isto, na verdade, é uma parte e parcela da perspectiva de Kinsella de que contratos de desempenho específicos são ilícitos ${ }^{18}$. Em contraste, nós os consideramos como aspectos crucialmente importantes do comércio. $\mathrm{Na}$ análise de Kinsella em 2003, a única maneira de assegurar que o animador aparecerá para cantar "Parabéns Para Você" em sua festa seria fazê-lo emitir como garantia uma obrigação que será confiscada caso ele não compareça ao local do evento para cumprir o prometido. Parece cruel arrastá-lo à força para o palco e forçá-lo a cantar sob ameaça da imposição de violência física. A maior parte das pessoas dirá que, caso faça isso, você seria culpado de lesão e agressões, enquanto o cantor de má vontade pareceria como uma vítima inocente. Mas considere o seguinte caso, mais simpático, para conseguir o cumprimento de um contrato de desempenho específico. X é um equilibrista que consegue andar 30 metros na corda-bamba. Ele contrata $Y$ para que mantenha uma rede de segurança logo abaixo, de modo a apanhar $X$ caso venha a cair. $Z$ é o guarda-costas de $X$, armado com uma pistola, mas por alguma razão vê-se impossibilitado de vigiar a tarefa de $\mathrm{Y}$. X caminha sobre a corda e Y o acompanha por baixo, segurando a rede. Quando X completa a metade do caminho, Y decide abandonar seu trabalho. $Z$ ameaça atirar em $Y$ caso ele se retire, deixando $X$ em apuros. Kinsella e, presumivelmente, também Davidson, veem $Z$ como a pessoa que está errada, dado que sua ameaça constitui uma tentativa de obrigar Y a realizar uma performance específi$\mathrm{ca}$, manejando a rede. Em contraste, assumimos a posição de que o criminoso é $Y$, enquanto $Z$ age de uma maneira completamente virtuosa ${ }^{19}$.

18 KINSELLA, Stephan N. A Libertarian Theory of Contract: Title Transfer, Binding Promises, and Inalienability.

${ }^{19}$ Para posições favoráveis à escravidão voluntária, o contrato de desempenho específico mais extremo de todos, ver: ANDERSSON, Anna-Karin. An Alleged Contradiction in Nozick's Entitlement Theory. Journal 
O ponto é que, independentemente de se o tomador de empréstimo do exemplo de Davidson "possui o título de Y para transferir", deve "transferir o título do dinheiro futuro Y no tempo de um ano". Deve ser obrigado a devolver o dinheiro do prestamista, caso contrário o tomador do empréstimo deveria ser considerado como ladrão. Como tal, deveria ser forçado a compensar sua vítima, deveria ser colocado na prisão e condenado a realizar trabalhos forçados, caso seja a única maneira de que os fundos possam ser devolvidos a seu proprietário legítimo ${ }^{20}$. Devemos conceder

of Libertarian Studies, Vol. 21, No. 3 (Fall 2007): 43-63; BLOCK, Walter E. Market Inalienability Once Again: Reply to Radin. Jefferson Law Journal, Vol. 22, No. 1 (Fall 1999): 37-88; BLOCK, Walter E. Alienability, Inalienability, Paternalism and the Law: Reply to Kronman. American Journal of Criminal Law, Vol. 28, No. 3 (Summer, 2001): 351-371; BLOCK, Walter E. Are Alienability and the Apriori of Argument Logically Incompatible? Dialogue, Vol. 1, No. 1 (2004); BLOCK, Walter E. Ayn Rand and Austrian Economics: Two Peas in a Pod. The Journal of Ayn Rand Studies, Vol. 6, No. 2 (Spring 2005): 259-269. BLOCK, Walter E. Epstein on Alienation: A Rejoinder. International Journal of Social Economics, Vol. 33, Nos. 3-4 (2006): 241-260; BLOCK, Walter E. Secession. Dialogue, No. 4 (2007): 1-14; FREDERICK, Danny. Voluntary Slavery. Las Torres de Lucca: Revista Internacional de Filosofía Política, Vol. 3, No. 4 (2014): 115-37; KERSHNAR, Stephen. A Liberal Argument for Slavery. Journal of Social Philosophy, Vol. 34, No. 4 (2003): 510536; LESTER, Jan Clifford. Escape from Leviathan: Liberty, Welfare and Anarchy Reconsidered. New York: St. Martin's Press, 2000; BIONIC MOSQUITO. The Sanctity of Contract. (April 19, 2014). Disponível em: <http://bionicmosquito.blogspot.com/2014/04/thesanctity-of-contract.html>; NOZICK, Robert. Anarchy, State and Utopia. New York: Basic Books, 1974. p. 58, 283, 331; STEINER, Hillel. An Essay on Rights. Oxford: Blackwell Publishers, 1994. p. 232; THOMSON, Judith Jarvis. The Realm of Rights. Cambridge, MA: Harvard University Press, 1990. p. 283-284.

${ }^{20}$ BLOCK. Market Inalienability Once Again: Reply to Radin; BLOCK, Walter E. Toward a Libertarian Theory of Guilt and Punishment for the Crime of Statism. In: HÜLSMANN, Jorg Guido \& KINSELLA, Stephan (Eds.). Property, Freedom and Society: Essays in Honor of Hans-Hermann Hoppe. Auburn, AL: Ludwig von Mises Institute, 2009. p. 137-148; BLOCK, Walter E. ; BARNETT II, William \& CALLAHAN, Gene. The Paradox of Coase as a Defender of Free que se o contrato original for lido de acordo com a interpretação de Davidson e Kinsella, então e somente nesse caso seria inadequado forçar o tomador do empréstimo a compensar o prestamista. No entanto, se isto não estiver especificado de outra forma e, especialmente, se o contrato entre os dois exigir que o tomador do empréstimo indenize totalmente o credor, nesse caso a posição de tanto Davidson quanto Kinsella parece estar em desacordo com a teoria libertária, ou pelo menos com a versão que apoiamos. Suponha que A deposite fundos com B por um ano, e que B empreste esses fundos a $C$ por um ano. Infelizmente, C investiu o dinheiro de boa-fé, porém cometeu um erro empresarial e não tem condições de reembolsar $\mathrm{B}$ ao término do período de um ano, com a consequência de que B não pode reembolsar A (observe que este não é um caso de BSLL ou de qualquer outro tipo de descasamento de maturidade). A lei ainda consideraria B um ladrão e o colocaria na cadeia caso não pudesse honrar seu compromisso com $\mathrm{A}^{21}$ ? Parece-nos que uma possível resolução seria que a cláusula contratual implícita de Davidson apresenta uma debilidade. Suponha que, ao invés do contrato ser lido como "o prestamista concorda em transferir o título do dinheiro presente $X$ hoje, se o tomador do empréstimo concordar em transferir o título

Markets. NYU Journal of Law \& Liberty, Vol. 1, No. 3 (2005): 1075-1095; GREGORY, Anthony \& BLOCK, Walter E. On Immigration: Reply to Hoppe. Journal of Libertarian Studies, Vol. 21, No. 3 (Fall 2007): 25-42; KINSELLA, Stephen. Punishment and Proportionality: the Estoppel Approach. The Journal of Libertarian Studies, Vol. 12, No. 1 (Spring 1996): 51-74; MORRIS, Herbert. Persons and Punishment. The Monist, Vol. 52, No. 4 (October 1968): 475-501; OLSON, Charles B. Law in Anarchy. Libertarian Forum, Vol. XII, No. 6 (Nov.Dec. 1979): 4; ROTHBARD. The Ethics of Liberty, p. 88; WHITEHEAD, Roy \& BLOCK, Walter E. Taking the Assets of the Criminal to Compensate Victims of Violence: A Legal and Philosophical Approach. Wayne State University Law School Journal of Law in Society, Vol. 5, No. 1 (Fall 2003): 229-254.

${ }^{21}$ Não. C seria quem estaria quebrado e passível de ser preso como devedor, e não $\mathrm{B}$. $\mathrm{C}$ teria um débito para com $A$, e não $B$. 
do dinheiro futuro $\mathrm{Y}$ no tempo de um ano, se o tomador do empréstimo tiver o título de $Y$ para transferir", seja na verdade lido como "o prestamista concorda em transferir o título do dinheiro presente $X$ hoje, se o tomador do empréstimo concordar em transferir o título do dinheiro futuro $\mathrm{Y}$ no tempo de um ano, se o tomador do empréstimo tiver o título de $Y$ no prazo de um ano, dado que se o tomador do empréstimo não tiver o título de $\mathrm{Y}$ em um ano, isso não se deve ao fato de que o tomador de empréstimo tenha participado de um contrato incompatível". Por que Davidson pode decidir o termo implícito?

A seguir, considere a afirmação de Davidson" 22 no sentido de que "todas as transferências de títulos orientadas para o futuro implicam em promessas de algum tipo". De modo algum. Uma promessa é algo totalmente diferente de uma obrigação contratual. Um homem promete um carro à sua mulher como presente de Natal. Não dá o carro. É uma conduta ética? Não, claro que não. Quebrar uma promessa é imoral. Mas isso faz dele um criminoso? Seria ingênuo sequer a cogitar isso. Agora considere um outro caso. Alguém paga a um vendedor de automóveis 10.000,00 dólares por um carro, a ser entregue no dia seguinte. $\mathrm{O}$ vendedor renega. Ele é antiético? Sim, com certeza. Ademais, também é um criminoso. Com toda a certeza. Ele roubou, não somente aquela quantidade de dinheiro, mas também o veículo, cuja propriedade agora pertence ao comprador que pagou pelo bem. Esse vendedor de automóveis deveria ser obrigado, sob ameaça de uma arma caso necessário, a devolver o carro? Pode apostar que sim. E se, por alguma razão, não puder fazer isso, deveria ser preso e colocado sob trabalhos forçados até que possa produzir fundos suficientes para compensar sua vítima, ou o mais próximo disso que conseguir, neste vale de lágrimas. Os dois casos são, portanto, muito diferentes.

22 DAVIDSON. Ethical Differences Between Loan Maturity Mismatching and Fractional Reserve Banking: A Natural Law Approach. p. 8.
Rothbard assevera:

Suponha que Smith e Jones façam um contrato. Smith entrega 1.000,00 dólares a Jones no momento presente, em troca de um vale de Jones, que concorda em pagar a Smith 1.100,00 dólares em um ano a partir de agora. Este é um típico contrato de dívida. $\mathrm{O}$ que aconteceu foi que Smith transferiu seu título de propriedade de 1.000,00 dólares no presente em troca da concordância de Jones, agora, de transferir um título de 1.100,00 dólares para Smith daqui a um ano. Suponha que, quando chega essa data, Jones se recusa a pagar. Por que este pagamento deveria ser passível de cumprimento sob uma lei libertária? A lei existente [...] sustenta amplamente que Jones deve pagar 1.100,00 dólares porque 'prometeu' pagar e essa promessa estabeleceu, na mente de Smith, a 'expectativa' de que receberia o dinheiro ${ }^{23}$.

Nosso argumento, aqui, é que meras promessas não correspondem a transferências de títulos de propriedade; que enquanto pode ser a coisa certa moralmente manter as promessas que fazemos, não é e não pode ser função da lei (ou seja, da violência legal) forçar o cumprimento da moralidade (neste caso, o cumprimento de promessas) em um sistema libertário. Nosso ponto, aqui, é que Jones deve pagar 1.100,00 dólares a Smith porque já concordou, por meio de um contrato, com essa transferência de título, portanto não pagar significa que Jones é um ladrão, alguém que roubou a propriedade de Smith. Em resumo, a transferência original que Smith realizou de 1.000,00 dólares não foi absoluta, mas sim condicional, condicionada ao pagamento de 1.100,00 dólares que Jones realizaria em um ano. Assim, portanto, deixar de pagar configura especificamente um roubo da propriedade que é de Smith por direito.

Porém Davidson não faz nada disso. Ela sustenta, ao contrário, que:

o contrato é diferente, contudo, porque a titularidade da propriedade não é completamente dada e assim, ao contrário do devedor no contrato de empréstimo, o locatário não

\footnotetext{
${ }^{23}$ ROTHBARD. The Ethics of Liberty. p. 133
} 
pode dispor de todos os aspectos da propriedade tal como deseja (realizando trocas com uma terceira parte, por exemplo) ${ }^{24}$.

No entanto, em geral, mas não sempre, há disposições a respeito do que pode ser feito com o empréstimo. Por exemplo, o tomador do empréstimo pode ser proibido de jogar esse montante em Las Vegas. Ou, para voltar ao assunto sob discussão, pode ser proibido de emprestá-lo para outra pessoa $C$, por um prazo maior (10 anos) do que o prazo pelo qual está tomando emprestado de A (1 ano).

Uma coisa é que B empreste o dinheiro de A com uma dimensão temporal de um ano para $C$, também pela mesma duração. De fato, existe o risco de que $C$ possa não devolver os fundos a $\mathrm{B}$ ao término do período de doze meses. Se isso acontecer, B não terá nada com o que indenizar A nesse momento. Mas algo totalmente diferente é que B empreste o dinheiro que A depositou com ele durante um ano para uma terceira pessoa, C, por toda uma década. Uma forma de analisar isto, no sentido de Davidson, e também de Bagus e Howden, é que, ao fazer isso, B assumiu um risco adicional $^{25}$. Neste caso, B ou terá que encontrar um poupador adicional, A2, para que possa ter condições de devolver o dinheiro de $\mathrm{A}$ ao término do período contratual de um ano; ou, possivelmente, B poderia renegociar com $\mathrm{C}$ a devolução antecipada desse empréstimo a dez anos. Ou, ainda, B poderia pagar utilizando seus próprios recursos. É por causa disto que os bancos têm exigências legais de capital, ou seja, uma quantidade de capital mínima (patrimônio líquido) com base em seus ativos "ponderados pelo risco".

Outra maneira de olhar para isto é que $\mathrm{B}$ realizou dois contratos incompatíveis. Um com A, o outro com C. Vamos considerar outros contratos incompatíveis similares. Y con-

24 DAVIDSON. Ethical Differences Between Loan Maturity Mismatching and Fractional Reserve Banking: A Natural Law Approach. p. 10.

${ }^{25} \mathrm{Ou}$, mais propriamente, B sujeitou A a este perigo adicional de não receber seu dinheiro de volta. corda em encontrar-se com $X$ no momento $t_{1}$ e na cidade $x$. Ao mesmo tempo, concordou em cantar no casamento de $Z$ em outra cidade distante, $Z^{26}$. É óbvio que $Y$ não pode cumprir ambos os contratos. Y fez algo perverso? Sim, claro. Antiético? Sem dúvida. No entanto, isto seria ilegal sob a lei libertária? Novamente, devemos responder de maneira afirmativa. Se isto não configura uma fraude, então nada mais o é. Y está cometendo uma fraude pelo menos contra $X$ ou Z. Possivelmente, contra ambos $^{27}$. Não se pode esperar, de qualquer um que faça dois contratos desse tipo, que não possa vitimar ambos. Considere agora um caso diferente. Uma mãe promete um brinquedo especial para suas duas crianças. Existe somente um desses brinquedos. Nenhum outro irá servir. Qualquer outro não passará de uma mera falsificação. Não há substitutos. Ou, de maneira mais próxima de nossas considerações, há muitos desses brinquedos à disposição, por exemplo bonecas Barbie, porém a mãe dispõe de recursos para comprar somente um desses brinquedos e não tem perspectivas de conseguir mais fundos até a época do cumprimento da promessa. Estes são exemplos de promessas incompatíveis. Antiético? Sim. Ilegal? Não, dado que não passam de promessas, e não obrigações contratuais.

Em contraste, suponha que B simplesmente torra o dinheiro confiado a ele por $\mathrm{A}^{28}$. Será que agora B aumentou o risco de não ser capaz de reembolsar A daqui a um ano? Sim, obviamente. Ele poderia devolver o dinheiro a A mais facilmente caso o tivesse enfiado debaixo do colchão, ou emprestado a $C$ por um

\footnotetext{
${ }^{26}$ Com base nesta nomenclatura, $t_{0}$ seria o momento presente, $t_{1}$ corresponde a um ano a partir de hoje, $t_{10}$ corresponde a dez anos a partir de agora e assim por diante.

${ }^{27}$ É óbvio que a lei existente, tal como a lei libertária, reconhece o conceito de de minimis.

${ }^{28}$ Assumimos que este ato não foi proibido no contrato entre A e B.
} 
ano, ou mesmo por dez anos ${ }^{29}$. No entanto, B cometeu uma fraude ao destruir o dinheiro que A confiou a ele durante um ano? Não. A despeito de parecer um pouco estranho, neste caso B não terá cometido fraude. Não se envolveu em dois contratos incompatíveis, um dos quais precisa necessariamente quebrar para satisfazer o outro.

\section{V - Teoria da TransferênCIA DE Títulos Aplicada aos Empréstimos} a Prazo

Davidson defende a seguinte proposição: Assim, enquanto A entrega a B o título de 100 dólares de dinheiro presente, $B$ não pode dar a A o título de 100 dólares de dinheiro futuro. Mais propriamente, A recebe o título de um bem presente, que é um direito sobre 100 dólares de dinheiro futuro. O bem que A recebe é o direito, e não o próprio dinheiro futuro ${ }^{30}$.

Aqui, insistimos, ao final do primeiro ano há duas pessoas, $\mathrm{A}$ e $\mathrm{C}$, não somente uma, com um direito sobre o dinheiro que A depositou com B e que B emprestou a C. Se é dessa maneira que ela definirá os títulos, então dizemos que se trata de títulos frouxos. Se há ou não títulos formais para esta propriedade, não vem ao caso. A lei libertária baseia-se em direitos e está claro que tanto A quanto $C$ têm um direito a este dinheiro. Observe que, usando o conceito correto de Davidson de que

\footnotetext{
${ }^{29}$ Neste caso, B pode ao menos contar com o valor presente descontado do dinheiro a ser recebido daqui a uma década, para servir como colateral para um outro empréstimo de algum A2. Isto é melhor do que perder dinheiro.

30 DAVIDSON. Ethical Differences Between Loan Maturity Mismatching and Fractional Reserve Banking: A Natural Law Approach. p. 12. Certamente, Davidson quis dizer que A receberia o direito de reivindicar algo mais que 100 dólares em um ano. Consideramos isto como não mais que um erro tipográfico de sua parte. Ou talvez ela esteja pensando em termos da política atual do FED (Sistema de Reserva Federal), segundo a qual a taxa de juros é praticamente zero.
}

para seu depósito de 100 dólares A recebeu um direito a 100 dólares no futuro, ao término desse ano esse direito venceu e A tem o direito sobre esse objeto, a saber, 100 dólares. Assim, um ano depois da interação comercial inicial, tanto A quanto $\mathrm{C}$ têm um direito sobre aquela quantidade de dinheiro presente. A fraude dos contratos incompatíveis ocorreu no início do BSLL e não um ano depois. Ela apenas se revela naquele momento temporal posterior.

Davidson prossegue:

Surge muita confusão devido a dois significados distintos da palavra 'direito' neste contexto. No primeiro sentido, um direito sobre um bem a ser entregue no futuro emerge de uma promessa feita pelo devedor e constitui evidência de uma transação de crédito não completada. Não é um título. Entretanto, no segundo sentido, um direito refere-se à propriedade de um bem presente. Em outras palavras, é um título, ou então evidência de que há um ${ }^{31}$.

Promessas, meras palavras. A razão de por que há uma dificuldade no tempo $t_{1}$ não decorre de qualquer "promessa". Mais propriamente, o problema emerge do fato de que há duas pessoas com um direito, uma reivindicação, um título, chame como quiser, a uma única quantidade de dinheiro, aqueles 100 dólares. A e C são os proprietários legítimos desse mesmo dinheiro; cada um possui 100 por cento dele. B pode contorcer o quanto quiser; isto não pode ser negado. Sim, B pode, possivelmente, recorrer a um outro depositante A2 e/ou renegociar com C para receber esses fundos antecipadamente, ou pode compensar utilizando seus próprios ativos. No entanto, caso fracasse, ficará exposto como impostor ${ }^{32}$. Ademais, logo no início, quando B realizou esses dois contratos incompatíveis, não há "dinheiro futuro" ${ }^{33}$. Na verdade, o que ela cha-

\footnotetext{
${ }^{31}$ Idem. Ibidem.

${ }^{32}$ Ele envolveu-se em uma fraude não em $t_{1}$, mas sim em $t_{0}$.

${ }^{33}$ Poderíamos pensar que, diante da afirmação de
} 
ma de "dinheiro futuro" ${ }^{34}$ pode existir somente como dinheiro presente e somente caso se materialize no instante temporal relevante, o ponto no qual B deve a A o dinheiro que agora está nas mãos de $C^{35}$.

Davidson força a barra em sua interpretação de que uma interação comercial bancária no fundo não passa de uma "promessa". Assevera: [...] A abre mão para sempre do título entregue originalmente a $\mathrm{B}$ e a seguir transferido para C. Sob nenhuma circunstância A possui simultaneamente os 100 dólares que são

Davidson de que "é óbvio que [...] bens futuros não existem" (DAVIDSON. Ethical Differences Between Loan Maturity Mismatching and Fractional Reserve Banking: A Natural Law Approach, nota 11), ela não precisaria recorrer tão vigorosamente a este conceito falacioso. Entretanto, logo após esta afirmação correta, a autora diz: "Na verdade, o que existe não passa de expectativas presentes a respeito de bens futuros". Não. Se "bens futuros não existem", então não pode haver expectativas a respeito deles. O que ela deveria ter realmente dito era: "Na verdade, não existe nada além de expectativas presentes" de bens que tornar-se-ão disponíveis no futuro. De fato, não existe isso de alguma coisa futura. Ofuturo se refere a algo queé desconhecido e incognoscível, embora não seja inimaginável. A este respeito, ver: LACHMANN, Ludwig. From Mises to Shackle: An Essay on Austrian Economics and the Kaleidic Society. Journal of Economic Literature, Vol. 14, No. 10 (March 1976): 54-62; LACHMANN, Ludwig. On the Central Concept of Austrian Economics: Market Process. In: DOLAN, Edwin G. (Ed.). Foundations of Modern Austrian Economics. Kansas City: Sheed \& Ward, 1976; LACHMANN, Ludwig. The Role of Expectations in Economics. In: LACHMANN, Ludwig. Capital, Expectations and the Market Process. Kansas City: Sheed, Andrews \& McMeel, 1977; LACHMANN, Ludwig. Capital, Expectations and the Market Process. Kansas City: Sheed, Andrews \& McMeel, 1977; LACHMANN, Ludwig. An Austrian Stocktaking: Unsettled Questions and Tentative Answers. In: SPADARO, Louis M. (Ed.). New Directions in Austrian Economics. Kansas City: Sheed, Andrews \& McMeel, 1978.

${ }^{34}$ Dinheiro futuro não passa de um subconjunto do conjunto de bens futuros, que é, em si mesmo, um conjunto vazio.

${ }^{35}$ Davidson (p. 12) cita Rothbard, que também se enreda no conceito falacioso de "dinheiro futuro". Ver: ROTHBARD, Murray N. Man, Economy and State. Scholar's Edition. Auburn AL: Ludwig von Mises Institute, 2004 [1962]. p. 800. propriedade de B. No momento em que A faz a negociação inicial, recebe de volta uma promessa - e essa promessa é de B - o que não é um título. Então, ao término do primeiro ano, se e somente se B possuir 100 dólares ou seu equivalente, então a reivindicação de $\mathrm{A}$ se transforma em um título sobre esses ativos. Em nenhum momento, A recebe de volta o título sobre os 100 dólares originais que foram repassados para $\mathrm{C}^{36}$.

Trata-se de uma surpresa revoltante, para todo depositante bancário na posição de A, que "A abriu mão para sempre de seu dinheiro". Se for assim, podemos ser perdoados facilmente por pensar que ninguém, em sã consciência, jamais depositaria dinheiro em uma conta de poupança em qualquer banco que seja. Oferecemos uma interpretação diferente para esta interação comercial: que A acredita totalmente que B tem a obrigação legal de devolver seus 100 dólares ao final do prazo de um ano. E que A acredita nisso independentemente de se "B possui 100 dólares ou seu equivalente $[\ldots]$ ". Na mente de $A$, se B tem ou não esse dinheiro, é algo que está a cargo, completamente, deste último ${ }^{37}$. A não quer ser incomodado com as histórias tristes de $\mathrm{B}$ a respeito da ausência dos fundos. Deseja apenas ter o reembolso, tal como estipulado no arranjo contratual que realizou com B no momento $t_{0}$. Dizer que "em nenhum momento A obterá de volta o título sobre os 100 dólares originais que foram repassados para $C^{\prime \prime}$ é algo muito distante do que se passava nas mentes dos envolvidos quando B realizou um

36 DAVIDSON. Ethical Differences Between Loan Maturity Mismatching and Fractional Reserve Banking: A Natural Law Approach. p. 14.

37 Observe que agora não estamos discutindo o momento presente, no qual o governo assegura os depósitos e o Banco Central funciona como um emprestador de última instância. Entretanto, em épocas anteriores e, neste sentido, melhores, os depositantes não consideravam a questão de se o banco teria fundos suficientes para reembolsá-los como uma "responsabilidade que corresponde completamente a este último [o banco]". Daí o fenômeno conhecido como corridas bancárias. 
contrato com $\mathrm{A}$ em $\mathrm{t}_{0}$. Isso explica as corridas bancárias.

Ademais, uma reivindicação válida é suficientemente boa para o libertarianismo. Como Davidson embasa sua análise nesta filosofia, encontra-se logicamente obrigada a concordar com este ponto de vista. Ela inclusive observa que A possui uma reivindicação válida, embora seja no primeiro dos dois sentidos que menciona.

Suponha, para fins de argumentação, que Davidson está correta em sua afirmação de que A não possui um título válido. No entanto, ela não disputa o conceito de uma reivindicação válida por parte de A. Deduzimos que há um choque de direitos de propriedade.

Consideremos, agora, a longa citação de Davidson, a seguir:

Suponha que A empresta a B 100 dólares durante um ano, tal como antes, e que B empresta imediatamente este dinheiro para $C$ por um período de 2 anos. Há uma duplicação de títulos de propriedade, conforme argumentam Barnett e Block? Não, não há. $\mathrm{A}$, que inicialmente possui os 100 dólares, transfere sua titularidade para $\mathrm{B}$, em troca da qual A recebe o título a um direito - uma letra de câmbio ou nota promissória - que estabelece que B promete reembolsar A dentro de um ano. B transfere o dinheiro e seu título para $\mathrm{C}$ e, em troca, $\mathrm{B}$ recebe o título para uma reivindicação diferente, a qual estipula que $\mathrm{C}$ promete devolver o dinheiro em dois anos. Em conjunto, há três títulos para três bens distintos, nenhum dos quais é uma duplicata. Dois destes bens são reivindicações e o outro corresponde aos 100 dólares. A possui uma reivindicação contra B; B possui uma reivindicação diferente contra $C$; e $C$ possui os 100 dólares $^{38}$. (A ênfase é nossa.)

Uma dificuldade que enfrentamos com esta explicação é que Davidson baseia-se fortemente no conceito de "promessas". Se substituímos esta palavra por "está sujeito a uma

38 DAVIDSON. Ethical Differences Between Loan Maturity Mismatching and Fractional Reserve Banking: A Natural Law Approach. p. 13. obrigação contratual", chegamos a uma conclusão totalmente diferente. Assim, B não está de fato "prometendo" nada, tal como reembolsar A ao final do período de um ano. Mais propriamente, está "sujeito, por obrigação contratual", a fazer isso, algo que é completamente distinto. Assim, B, no ponto inicial $\mathrm{t}_{0^{\prime}}$ quando A depositou primeiramente os 100 dólares com ele, "obrigou-se contratualmente" a reembolsar o dinheiro para A depois de um ano, em $t_{1}$. Nesse momento posterior, ao final do período de 12 meses, A é o proprietário legítimo desse dinheiro. Dado que Davidson permite que $C$ possua esses 100 dólares, então há duas pessoas, cada uma das quais com um direito de propriedade de 100 por cento sobre esses mesmos fundos, uma dificuldade que faz com que rejeitemos o BSLL como uma prática bancária ética.

Poderia ser ainda pior, dado que em nosso caso não há duplicação de direitos de propriedade. Há, entretanto, pelo menos a duplicação de uma reivindicação e de um direito de propriedade. Mas espere; Davidson concede o seguinte: "Para complicar de alguma forma a questão, a reivindicação, tal como usada neste primeiro sentido, é obviamente um bem presente em si mesma, a qual é propriedade do portador das notas. Portanto, tem um título" ${ }^{39}$. Logo, há uma duplicação, um conflito entre títulos de propriedade. Davidson volta e meia admite isto. A natureza abomina o vácuo. A teoria libertária, de maneira similar, abomina a sobreposição de títulos de propriedade.

Reconsidere o ponto de Davidson de que "A possui um direito de reivindicação contra B; B possui um direito de reivindicação diferente contra C; e C possui os 100 dólares" ${ }^{40}$. Isto é de fato verdadeiro. Entretanto, somente no momento temporal inicial $t_{0}$ e não depois que se passou o período de um ano. Assim, um ano depois, em $t_{1}$, em nítido contraste, $\mathrm{A}$ possui agora um título de propriedade legí-

\footnotetext{
${ }^{39}$ Idem. Ibidem.

${ }^{40}$ Obviamente, tanto a reivindicação de A contra B e a reivindicação de $\mathrm{B}$ contra $\mathrm{C}$ são bens presentes e, como tais, são propriedade.
} 
timo com respeito àquela quantidade de dinheiro. Mas C também possui. Se isso não for uma duplicação, então não existe nada mais que possa ser. Ou seja, a propriedade que A possui na forma de uma reivindicação contra B transforma-se, ao término do ano, em propriedade sobre os 100 dólares, enquanto a propriedade, na forma de uma reivindicação, expirou.

Davidson pergunta, a seguir, "e se $B$ fracassa em manter os 100 dólares com os quais reembolsar $A$, antes do final do primeiro ano?"41 Respondemos: esqueçamos, ao menos pelo momento, de se B pode ou não recorrer a um A2 ou utilizar seus próprios fundos para sair do aperto. Independentemente de poder fazer isso ou não, é suficiente para minar a validade legal e a moralidade do BSLL que, um ano depois, em $t_{1}$, tanto $A$ quanto $C$ tenham um título válido sobre essas verbas.

Nossa parceira neste debate, entretanto, elabora um ponto eminentemente razoável com respeito a $t_{1}$. De acordo com ela:

[...] em uma economia de mercado [...] na qual há muitos prestamistas no mercado, $\mathrm{B}$ pode certamente contar com uma expectativa razoável de que terá, de fato, a oportunidade de reembolsar A. [...] será capaz, em uma data posterior, de fazer um contrato com um A2 para conseguir fundos [...] com os quais poderá devolver o dinheiro a $\mathrm{A}$ $[\ldots]^{42}$.

41 DAVIDSON. Ethical Differences Between Loan Maturity Mismatching and Fractional Reserve Banking: A Natural Law Approach. p. 13.

42 Idem. Ibidem, p. 15. Isto é verdade, a partir de um ponto de vista, por sinal bastante otimista. Entretanto, no mundo real, na verdade o BSLL consiste em especulação antiética com o dinheiro de outras pessoas. Foi isto que causou os colapsos em vários mercados financeiros em 2008. Gill menciona "O espírito de Wilkins Micawber, o personagem de Dickens cujo lema em questões financeiras era 'algo vai aparecer...'“ (GILL, James. A Dickens of a Problem with the State Budget. The New Orleans Advocate (Sep. 3, 2015). Disponível em: <http://theadvocate.com/ news/opinion/13339856-123/james-gill-bobby-jindalhas $>$.). Este parece ser o lema daqueles que confiam no surgimento de um A2 para tirar o banco do aperto.
Porém, isto é, na verdade, uma prova excessiva. Pois Davidson se sai muito bem em sua oposição ao FRB com embasamento ético. Entretanto, exatamente o mesmo ponto pode ser levantado a respeito dessa prática bancária. Se A deseja utilizar seu depósito à vista, instantaneamente, e B não possui os fundos, ele também pode ter uma "expectativa razoável" de que será capaz de obter esses fundos de um A2, certamente a uma taxa de juros suficientemente alta. Como poderia fazer isto instantaneamente? Há um instante e depois há novamente um instante. Certamente, pode adiar A por um minuto ou dois e ainda estar dentro da rubrica "instante". B poderia ter se adiantado em um trato com um outro banco, digamos B2, para transferir dinheiro eletronicamente para B caso ele venha a estar em extrema necessidade disso; isto poderia ser recíproco ${ }^{43}$. Assim, se Davidson deseja ser logicamente consistente e aderir à visão de Davidson de que o FRB é de por si fraudulento ou então, por qualquer outra razão, ilícito, então ela deve manter o mesmo ponto de vista com respeito ao BSLL. O que vale para o FRB, também vale para o BSLL ${ }^{44}$.

${ }^{43}$ Isto não funcionaria muito bem se ambos os bancos, B e B2, precisassem de recursos imediatamente. Entretanto, "[...] em uma economia de mercado [...]", possivelmente haveria dúzias ou mesmo centenas de milhares de tais bancos.

${ }^{44}$ Este tipo de esquema Ponzi funciona muito bem até que cessa de funcionar. Então, existe um momento Minsky e todas as instituições que trabalhavam com BSLL precisam lutar por recursos ao mesmo tempo. A respeito disto, ver: CASSIDY, John. The Minsky Moment. The New Yorker (Feb. 4, 2008). Disponível em: <http://www.newyorker.com/magazine/2008/02/04/ the-minsky-moment>; MINSKY, Hyman P. The Financial Instability Hypothesis: A Restatement. Thames Papers in Political Economy. Reimpresso em: MINSKY, Hyman P. Can "It" Happen Again? Essays on Instability and Finance. Armonk, NY: M. E. Sharpe, 1984. p. 90-116; PRYCHITKO, David L. Competing Explanations of the Minsky Moment: The Financial Instability Hypothesis in Light of Austrian Theory. The Review of Austrian Economics, Vol. 32, No. 3 (2009): 199; YELLEN, Janet L. A Minsky Meltdown: Lessons for Central Bankers. Federal Reserve Bank of San Francisco (April 2009). Disponível em: <http:// 
Em $t_{1}$, sob BSLL, B encontra-se exatamente na mesma posição de B sob FRB em $t_{0}$. Ambos encontram-se totalmente sem rumo. Cada um desses Bs deve dinheiro que não possui, devido a suas próprias ações. Obviamente, o B do BSLL apresenta uma vantagem sobre o B do FRB: dispõe de um ano para preparar-se para esta eventualidade, para lidar com a duplicação dos direitos de propriedade. Isto dificilmente constitui, contudo, um embasamento sobre o qual sustentar uma teoria ética, a qual deveria basear-se em princípios e não em questões de temporalidade. Em todo caso, o B sob BSLL em $t_{0}$ em pouco tempo se tornará o $\mathrm{B}$ sob BSLL em $\mathrm{t}_{1}$ e então coincidirá com a situação do $B$ sob FRB em $t_{0}$.

Davidson faz uma distinção onde não há diferença real. Ela condena corretamente o FRB com base em que leva à duplicação de títulos. Duas pessoas distintas não podem, cada uma, possuir 100 por cento de uma mesma coisa ${ }^{45}$. Entretanto, em $t_{1}$ o B do BSLL encontra-se na mesma situação do B do FRB em $\mathrm{t}_{0}$. Em cada caso, há duas pessoas, A e C, que têm um direito de 100 por cento sobre o dinheiro. Davidson defende sua posição com base em que é possível encontrar um A2 em $t_{1}$ para o banqueiro do BSLL, ou então que $B$ possa pagar a partir de seus próprios recursos. Certamente, isto é possível. No entanto, o mesmo se aplica ao B do FRB no tempo $t_{0}$. Ele também pode, possivelmente, encontrar um A2 "instantaneamente". Aqui, definimos "instantâneo" como sendo alguns minutos. Os bancos abrem somente de segunda a sexta-feira, geralmente entre $10 \mathrm{~h}$ e $16 \mathrm{~h}$, que corresponde normalmente ao horário bancário ${ }^{46}$.

www.frbsf.org/our-district/press/presidents-speeches/ yellen-speeches/2009/april/yellen-minsky-meltdowncentral-bankers/>.

${ }^{45}$ Fazemos referência ao famoso filme de Mel Brooks, "Primavera para Hitler", no qual as velhinhas detêm dezenas de milhares da porcentagem da peça.

${ }^{46}$ Relevante, aqui, é a questão dos caixas eletrônicos. Um FRB pode não ser capaz de satisfazer ao desejo de seus depositantes de retirarem fundos imediatamente se os caixas eletrônicos ficarem sem dinheiro,
Para uma grande retirada, mesmo um banco com 100 por cento de reservas levaria uns poucos minutos para computar todo o dinheiro. Toda ação humana toma tempo. Nada, em termos estritos, é instantâneo. Assim, não venham nos dizer que um banco FRB não pode obter os fundos necessários de um A2. Desse modo, com a mesma base que Davidson utiliza para defender o BSLL, coloca-se em uma situação de reductio: vê-se logicamente obrigada a apoiar o FRB, algo que condena em diversas ocasiões.

De acordo com Davidson, "está claro que nem avisos de retiradas, nem cláusulas de opções alteram a análise ou criam qualquer tipo de continuidade entre os depósitos e os empréstimos a prazo ordinários" ${ }^{47}$. Estamos de acordo. No entanto, não nos baseamos em qualquer espécie de contínuo ${ }^{48}$ para sustentar o ponto de que a autora está logicamente obrigada a lidar com o FRB e o BSLL da mesma maneira, eticamente falando. Mais propriamente, para ela, são e devem ser uma coisa só. Com base no raciocínio que a autora emprega para rejeitar o FRB, encontra-se logicamente forçada a tratar o BSLL da mesma forma. Pois o FRB não passa, na realidade, de um caso especial do BSLL. Em ambas as situações, B se depara com um problema criado por si mesmo, tal como tentamos demonstrar.

Coloquemos isto à prova. Na perspectiva de Davidson:

Se B, agindo como intermediário, empresta novamente o dinheiro a $\mathrm{C}$, a reivindicação de A não é um título sobre o dinheiro que atualmente pertence a $C$. Ao invés disso, permanece como uma reivindicação: um direito de reivindicar contra B. Quando o empréstimo de A vence, supondo que B te-

mesmo que o banco tenha o dinheiro em seus cofres. Entretanto, o problema dos contratos conflitantes pode surgir através da utilização dos cartões de débito.

47 DAVIDSON. Ethical Differences Between Loan Maturity Mismatching and Fractional Reserve Banking: A Natural Law Approach. p. 19.

48 BLOCK, Walter E. \& BARNETT II, William. Continuums. Ethics \& Politics, Vol. 1 (June 2008): 151166. 
nha cumprido sua promessa, a reivindicação se transforma em um título sobre o dinheiro devido, atualmente em posse de B, mas não sobre o dinheiro em posse de C. Se, neste ponto, B não cumpriu sua promessa, a reivindicação de $\mathrm{A}$ permanece como uma reivindicação não satisfeita por $\mathrm{B}$ até o momento em que $B$ possa produzir o dinheiro ou outros ativos. Em qualquer caso, não surge nenhuma duplicação de títulos de propriedade, independentemente da duração do empréstimo de $B$ para $C$, ou do desempenho de $\mathrm{B}$ para com $\mathrm{A}^{49}$.

Tudo isto é perfeitamente aceitável desde que uma reivindicação não passe de uma mera promessa. Descumprir uma promessa pode ser antiético, mas, enquanto libertários, o que realmente nos preocupa é como a lei deveria ser nesses casos. Não estamos preocupados, diretamente, com a moralidade. Assim, se o direito de reivindicar não é mais do que uma mera promessa, podemos acompanhar a análise de Davidson. Entretanto, sustentamos que essa "reivindicação" é muito mais do que isso. Na verdade, é um título de propriedade legítimo. Sendo assim, então, realmente ocorre uma sobreposição de títulos de propriedade. E, novamente, a reductio ad absurdum vem à tona. No caso do FRB, o empréstimo de $\mathrm{A}$ "vence" em $t_{0}$. A (agora, no presente) possui um título lícito com relação ao dinheiro em questão. B não tem os recursos necessários, porém pode (talvez) obtê-los e de imediato. Assim, se o BSLL é legítimo na perspectiva da autora, por que isto não deveria também aplicar-se necessariamente ao FRB?

Na opinião de Davidson, o BSLL: “[...] nunca equivale a um círculo quadrado" ${ }^{50}$.

Títulos duplicados não são criados por este arranjo contratual. Mas, então, isso também vale para o FRB. Não é um contrato inválido para um banco sob BSLL, que não pode dispor dos recursos necessários para pagar

49 DAVIDSON. Ethical Differences Between Loan Maturity Mismatching and Fractional Reserve Banking: A Natural Law Approach. p.21.

${ }^{50}$ Idem. Ibidem. a A? Não? Isto é "somente" falência? Só que então isto também se aplica ao FRB. Nosso ponto não é propriamente demonstrar que o BSLL e ilícito: em vez disso, é uma tentativa de aplicar a reductio ad absurdum contra a posição de Davidson. Demonstramos que há uma grande semelhança entre o FRB e o BSLL, não em $t_{0}$, mas em $t_{1}$. Se esta equivalência existe, então, logicamente, nossa parceira no debate vê-se obrigada, caso deseje interpretar o FRB como ilegal sob a lei libertária, a chegar à mesma conclusão com respeito ao BSLL ${ }^{51}$.

\section{VI - ConClusÃo}

Resumimos nosso argumento no esquema a seguir.

A única diferença real entre o FRB e o BSLL é o timing. O primeiro é um caso especial do último. Sim, há, de certa forma, uma divergência entre os dois em $t_{0^{\prime}}$ mas não há nenhuma diferença em $t_{1}$. Em acréscimo, são parecidos quanto a serem vulneráveis à acusação de serem um esquema Ponzi, devido à sobreposição de títulos de propriedade e à incompatibilidade de contratos.

Um último ponto. Como podemos fazer uma distinção entre esta discussão e a prática de vender em mercados futuros? Ou seja, vender algo que ainda não temos, mas que pretendemos comprar no vencimento do contrato. Há um velho adágio que diz: “Aquele

${ }^{51}$ Uma pequena dificuldade com a análise de Davidson (p. 22) surge quando ela afirma: “[...] se o dinheiro é para ser utilizado propriamente como dinheiro, deve ser capaz de ser trocado [...]". Isto não soa verdadeiro para o subjetivismo austríaco que sabemos que a autora assume. Pois, de sua posição vantajosa, o dinheiro não precisa ser trocado. Em vez disso, pode ser adicionado a balanços de caixa. $\mathrm{O}$ dinheiro pode ser utilizado para uma variedade de propósitos e ainda permanecer como um meio de troca e de pagamentos finais geralmente aceito. Pode ser usado para aquecer uma casa, queimando-o na lareira. Pode ser usado como faz o Tio Patinhas, que toma banho em uma cascata de notas de 50 dólares; ou para encher uma piscina e fazer mergulhos. Pode ainda ser usado como papel de parede. 


\begin{tabular}{lcc} 
& FRB & BSLL \\
\hline Momento em que B deve a A & Imediatamente & Um ano \\
\hline Em t $_{0}$ & N. A. & Um ano \\
\hline Em t $_{1}$ & N. A. & Imediatamente \\
\hline Esquema Ponzi? & Sim & Sim \\
\hline Dois contratos incompatíveis? & Sim & Sim \\
\hline $\begin{array}{l}\text { Sobreposição de direitos de } \\
\text { propriedade? }\end{array}$ & Sim & Sim \\
\hline
\end{tabular}

que vende o que não é seu, deve comprá-lo de volta ou então ir para a cadeia". Na verdade, há uma grande diferença entre vender a descoberto em mercados futuros e vender a descoberto em mercados de ações. Nos mercados futuros, A promete pagar \$X a B em um certo momento no futuro e $B$ promete entregar Z para A nesse mesmo momento. Isto cria um contrato futuro que é valorizável como propriedade. Tanto A quanto B têm direitos e obrigações sob esse contrato, que cada um pode vender da maneira como quiser. Dizemos que A está comprado em $Z$ e que B está vendido em $Z$ (obviamente, pelo mesmo raciocínio, B está comprado em \$X e A está vendido em $\$ \mathrm{X})$. A tem o direito de receber $\mathrm{Z}$ no momento especificado e tem a obrigação de pagar \$X nesse mesmo momento;
B tem o direito a receber $\$ X$ no tempo determinado e a obrigação de entregar $Z$ nesse mesmo momento. Ignorando a margem que cada um deve colocar para assegurar o desempenho, para que ninguém seja prejudicado caso uma das partes se torne inadimplente, não há transferência de dinheiro ou de bens no momento em que o contrato é realizado; em vez disso, cada parte contrai a obrigação de entregar no momento que é especificado para a entrega. Ninguém vendeu nada até que o contrato expire; tudo o que cada um fez foi uma promessa de venda $-\mathrm{Z}$ por parte de B e \$X por parte de A. Mas nenhuma parte tem o direito de reivindicar qualquer coisa que seja ( $Z$ ou $\$ X$ ) até o momento estabelecido pelo contrato.cos 